Deception and truth detection when analysing nonverbal and verbal cues

\author{
Aldert Vrij ${ }^{1}$ \\ Department of Psychology, University of Portsmouth
}

${ }^{1}$ Correspondence concerning this article should be addressed to Aldert Vrij, Department of Psychology, University of Portsmouth, King Henry Building, King Henry 1 Street, PO1 2DY, Hants, United Kingdom. Email: aldert.vrij@port.ac.uk 


\begin{abstract}
In this article, I present my view on the significant developments and theoretical/empirical tipping points in nonverbal and verbal deception and lie detection from the last thirty years and on prospects for future research in this domain. I discuss three major shift in deception detection research: (i) from observing target persons' nonverbal behaviour to analysing their speech; (ii) from lie detection based on differences between truth tellers and liars’ levels of arousal to lie detection based on the different cognitive processes or strategies adopted to appear convincing; and (iii) from passively observing target persons to actively interviewing them to elicit or enhance verbal cues to deceit. Finally I discuss my ideas for future research, focussing on initiatives from my own lab. Hopefully, this will stimulate other researchers to explore innovative ideas in the verbal deception research domain which already has seen so much progress in the last decade.
\end{abstract}




\section{Deception and truth detection when analysing nonverbal and verbal cues}

\section{From observing behaviour to analysing speech}

The year 1988, when the first issue of Applied Cognitive Psychology appeared, coincided with the start of my career. More importantly, it also coincided with the introduction in English of Criteria-Based Content Analysis (CBCA), a verbal veracity tool which originated in Germany and Sweden in the 1950's (Köhnken \& Steller, 1988). CBCA consists of a list of 19 criteria which are thought to be more frequently present in truthful than in deceptive statements. This is called the 'Undeutsch hypothesis', named after one of the CBCA developers, German scholar Udo Undeutsch. The CBCA tool has been extensively examined. I am aware of more than 40 empirical CBCA studies (Vrij, 2018) in which the Undeutsch hypothesis was supported for 15 of the 19 criteria included on the CBCA-list (Amado, Arce, Fariña, \& Vilarino, 2016).

Until 1988, writings about lie detection mostly focused on analysing nonverbal behaviour. One of the early examinations of deceptive nonverbal behaviour was carried out by Reid and Arther (1953). Reid is one of the developers of the 'nine steps interrogation technique’, also called the Reid technique (Inbau, Reid, Buckley, \& Jayne, 2013), an accusatory style of interrogation (Meissner et al., 2014). This interrogation technique is still popular amongst practitioners, despite research showing that, compared to non-accusatory information-gathering interviewing techniques, it results in less information, fewer cues to deceit, fewer true confessions and more false confessions (Meissner et al., 2014). The Reid and Arther (1953) examination of nonverbal cues to deceit was an observation of real suspects' behaviours in real police interviews. It has an important limitation, however, typical of deception field research: The ground truth, the actual veracity status of the suspects, was unclear, which means that the study does not provide actual insight into the behaviour of suspects. More than one hundred deception studies -brilliantly summarised by Bella DePaulo 
and her colleagues (2003) in their meta-analysis- have shown that the cues Reid and Arther (1953) claimed to be diagnostic of deception, are actually unrelated to deception. Yet, these undiagnostic cues to deceit are presented as diagnostic cues in the Reid training manual (Inbau et al., 2013). Unsurprisingly, observers who paid attention to the cues promoted in the Reid training manual performed less well in lie detection tests than their counterparts (Kassin \& Fong, 1999; Mann, Vrij, \& Bull, 2004). The study by Mann et al. (2004) is interesting, because in that study police officers observed video-fragments of real police - suspect interviews (suspects of murder, rape and arson) (presented in Mann, Vrij, \& Bull, 2002). These suspects also did not display the behaviours which are promoted in the Reid manual. Unfortunately, the Reid group ignore all these research insights. Their writing about nonverbal cues to deception appear not to have changed much, if at all, since the 1950's.

Another influential publication about nonverbal cues to deception appeared in 1985: Paul Ekman's book Telling lies. His book is well known and often cited, and many people unfamiliar with deception research have heard of Ekman's ideas. Ekman claimed that liars reveal themselves by displaying facial micro-expressions of emotions and other involuntarily behaviours. The fictional character Dr. Cal Lightman in the TV drama series Lie to Me detects lies in the way described by Ekman. Ekman's book is very well written and -at the time of publication- presented innovative ideas about deception and lie detection. However, Ekman has seldom, if ever, published empirical evidence to support the views presented in his book. Perhaps for this reason, his influence has greatly diminished amongst deception researchers over time.

The DePaulo et al. (2003) meta-analysis showed that nonverbal cues to deceit are weak and unreliable. This was, in 2006, followed by a meta-analysis about observers' ability to detect deceit when observing nonverbal and verbal cues to deception (Bond \& DePaulo, 2006). Like the DePaulo et al. (2003) meta-analysis, it was a comprehensive and ground 
breaking analysis, including the judgements of nearly 25,000 observers. On average, $54 \%$ of their judgments were correct, a performance just better than chance (50\%). The medium to which observers were exposed affected the accuracy of their judgments. When they could only see the target person, they performed worse (52\% accuracy) than when they could only hear the target person (63\%). The same pattern of findings emerged when police officers assessed truths and lies by suspects in real police interviews (Mann, Vrij, Fisher, \& Robinson, 2008). This suggests that access to verbal content facilitates discrimination between truths and lies. This could be explained by taking into account the strategies truth tellers and liars use when they attempt to make a convincing impression on others.

The nonverbal strategies liars and truth tellers employ when their veracity is under scrutiny are similar: Both try to suppress signs of nervousness and attempt to replace this by signs which they believe appear honest, such as looking conversation partners in the eye and suppressing nonverbal cues such as scratching the head and wrists (Hartwig, Granhag, Strömwall, \& Doering, 2010; Vrij, Mann, Leal, \& Granhag, 2010). In contrast, the verbal strategies used by truth tellers and liars differ (Hartwig, Granhag, \& Strömwall, 2007). Truth tellers employ a 'tell it all' strategy whereas liars employ a 'keep it simple' strategy. The direct result of this is that truthful stories often include more details than deceptive stories: The number of details in an account, a verbal cue included in the CBCA list, emerged as the most diagnostic cue of all 19 CBCA cues ( $d=.77$, Amado et al., 2015).

The topic of nonverbal cues to deception continues to attract much attention in popular writings and the media, perhaps because it sounds so intriguing. Take, for example, Ekman's approach. He claims that liars leak nonverbal signals of deceit without being aware of it and only the highly skilled observer will be able to spot these leakages. This almost sounds like science fiction! Over the last fifteen years, research into nonverbal cues to deception has been in decline, with the possible exception of research into reaction times 
(Verschuere, Köbis, Bereby-Meyer, Rand, \& Shalvi, 2018). Research into speech differences between truth tellers and liars is now dominant. This is perhaps the result of the two metaanalyses discussed earlier (Bond \& DePaulo, 2006; DePaulo et al., 2003), which showed only weak effects for nonverbal deception cues in lie detection. Those meta-analyses certainly contributed to my decision to pay less attention to nonverbal cues in our research.

This does not mean that nonverbal deception research should be completely disregarded. There are many situations in which investigators have little else to go on than observing behaviours, for example, when attempting to spot wrongdoers in public spaces such as airports, public transport, and sporting events or when surveying CCTV footage. I am not aware of any published peer-reviewed research examining how wrongdoers and innocents behave in such situations. In general, the nonverbal deception research carried out to date does not fit with situations in which such assessments are important or practical (Vrij, Hartwig, \& Granhag, 2018). The vast majority of deception research has addressed a setting in which the target speaks (for a brief period), but where there is no real interaction between the target and the interviewer. This is not a realistic; in fact, we could not produce one single example that illustrates this setting (Vrij, Hartwig, \& Granhag, 2018). In addition, in such situations observing behaviours is not necessary and investigators could analyse speech instead. The overall conclusion is that researchers should examine nonverbal communication in settings where no speech is available and a nonverbal analysis is thus required.

Before the introduction of CBCA in English-speaking journals in 1988, researchers examined speech but did so in a different manner. They mainly examined speech characteristics such as generalising terms (The use of words such as “always”, “never”, “nobody” or "everybody”), self-references (The use of words referring to the speaker himself/herself such as “I”, “me” or "mine”) and lexical diversity (Number of different words in a statement divided by the total number of words used in that statement) (Vrij, 2008). The 
important difference with CBCA is that such speech characteristics do not reveal much about the information provided in a statement, whereas CBCA does, because it concentrates on the different types of detail (pieces of information) someone provides. This focus on the information provided is important because it brings verbal lie detection in alignment with another main aim of an investigative interview: to collect as much accurate information as possible (Fisher, 2010). Not long after the introduction of CBCA in English-speaking journals an alternative verbal lie detection tool was introduced, Reality Monitoring, or RM (AlonsoQuecuty, 1992; Sporer, 1997, 2004). RM has been developed by Marcia Johnson as a method to distinguish between memories based on real experiences or imagination (Johnson, 1988, 2006). Researchers subsequently extend RM to a lie detection method. Like CBCA, RM focuses on the information (details) someone provides, but RM has, compared to CBCA, a stronger theoretical rationale and is simpler to teach and use (Sporer, 2004; Vrij, 2008). Perhaps for these reasons, deception researchers nowadays mainly focus on the verbal details that are part of RM (mainly perceptual information, spatial information and temporal information) rather than on the CBCA criteria. Research has shown that the RM details are more likely to occur in truthful than deceptive statements (Masip, Sporer, Garrido, \& Herrero, 2005; Vrij, 2018), and that CBCA and RM produce similar results in terms of accuracy in truth and lie detection (Vrij, 2018).

\section{From arousal-based to cognition-based lie detection}

Apart from a shift in turning attention from behaviour or speech characteristics to speech content, a second important shift in deception research was the shift from lie detection based on truth tellers' and liars' different levels of arousal, to lie detection based on the different cognitive processes or strategies adopted to appear convincing. The 2003 report from the (US) National Research Council (NRC) in polygraph testing has played an influential role in this. First, the NRC concluded that there is no theory available as to why liars would 
necessarily experience more arousal (e.g. why they necessarily would be more nervous) than truth tellers. Indeed, truth tellers can be nervous too when they are interviewed or when they feel observed in high stress situations (Bond \& Fahey, 1987). Second, the NRC concluded that is not possible to ask questions that would necessarily make liars more nervous than truth tellers.

Cognition-based lie detection differs from arousal-based lie detection mainly regarding the second point. Interview protocols have started to emerge that trigger different mental processes or verbal strategies in truth tellers and liars and, subsequently, elicit or enhance verbal differences between them. This line of research represents the third paradigm shift in deception research: From passively observing target persons to actively interviewing them (Vrij \& Granhag, 2012). I briefly summarise the four approaches that, in my view, have shown the best results and the best potential in terms of lie detection (Vrij, 2018).

Strategic Use of Evidence (SUE). Truth tellers and liars employ different strategies during an interview. Truth tellers are generally forthcoming, whereas liars try to prevent revealing incriminating information through avoidance (e.g. avoiding mentioning in a free recall where they were at a specific time) or denials (e.g. denying having been at a certain place at a specific time when asked directly; Granhag \& Hartwig, 2008, 2015). By asking questions related to the evidence without making the interviewee aware that they possess this evidence, investigators can make these different strategies apparent: Truth tellers’ accounts are typically more consistent with the available evidence than liars’ accounts (Hartwig, Granhag, \& Luke, 2014). In addition, sometimes in an interview, liars start to realise that the interviewer may hold some incriminating evidence against them. They then respond by changing their statement and trying to provide an innocent explanation for this evidence. This results in liars showing more within-statements inconsistencies than truth tellers (Hartwig et al., 2014). 
Assessment Criteria Indicative of Deception (ACID). The ACID interview procedure is based on the Cognitive Interview, a well-established protocol to elicit more information from cooperative witnesses through the use of specific memory-enhancement tools, termed 'mnemonics' (Fisher \& Geiselman, 1992). Amongst other findings, ACID research has shown that truth tellers report more additional information in response to these mnemonics than liars (Colwell, Hiscock-Anisman, \& Fede, 2013; Colwell, Hiscock-Anisman, Memon, Taylor, \& Prewett, 2007).

Cognitive Credibility Assessment (CCA). The CCA technique comprises three elements: (i) Imposing cognitive load; (ii) Encouraging interviewees to say more, and (iii) Asking unexpected questions (Vrij, Fisher, \& Blank, 2017; Vrij, Fisher, Blank, Leal, \& Mann, 2016).

(i) Imposing cognitive load. In interview settings lying is typically more mentally taxing than truth telling (see fMRI research, Christ et al. 2009). Investigators can exploit this by making the interview setting cognitively more difficult, for example by asking interviewees to engage in a concurrent, second, task when discussing the event. Liars, who have to spend more effort on their story telling, are less able than truth tellers to cope with such additional requests (Debey, Verschuere, \& Crombez, 2012). It can also impair their story telling ability (Evans, Michael, Meissner, \& Brandon, 2013).

(ii) Encouraging interviewees to say more. In interview settings, truth tellers typically do not provide all the information stored in their memory (Fisher, 2010; Vrij, Hope, \& Fisher, 2014). One reason is that they do not know how much information they are expected to provide. One effective way to raise truth tellers' expectations about how much information to provide is to let them listen to a model statement (MS), which is an example of a detailed account/story unrelated to the topic of the interview (Leal, Vrij, Warmelink, Vernham, \& Fisher, 2015). Although a MS results in more information from both truth tellers and liars 
(Bogaard, Meijer, \& Vrij, 2014; Ewens et al., 2016b; Leal et al., 2015), differences emerge in the quality of the information they provide. For example, after an MS, truth tellers included more complications in their stories than liars (Vrij, Leal et al., 2017) and their stories sounded more plausible (Leal et al., 2015), whereas liars reported more peripheral information than truth tellers (Leal, Vrij, Deeb, \& Jupe, 2018).

(iii) Asking unexpected questions. Liars typically prepare themselves for interviews by considering answers to questions they anticipate being asked (Hartwig, Granhag, \& Strömwall, 2007). However, they cannot know which questions will be asked. When investigators ask a mixture of anticipated and unanticipated questions, truth tellers answer each with similar ease, but liars find answering the unanticipated questions more difficult than answering the anticipated questions (Lancaster, Vrij, Hope, \& Waller, 2012).

Verifiability Approach (VA). The VA tries to exploit a dilemma liars face. On the one hand, they prefer to provide many details, because detailed accounts are more likely to be believed (Bell \& Loftus, 1989; Nahari, Vrij, \& Fisher, 2012). On the other hand, they do not like to present many details out of fear that they are checked by investigators, which could subsequently give the lie away (Nahari et al., 2012). To solve this dilemma, liars typically report fewer details that can be checked by investigators than truth tellers (Nahari, 2018; Vrij \& Nahari, in press). This effect becomes stronger when interviewees are asked to include, where possible, details in their statement that the investigator can check, because it results in truth tellers adding more checkable details to their accounts than liars (Harvey, Vrij, Nahari, \& Ludwig, 2016; Nahari, Vrij, \& Fisher, 2014b).

\section{Future Research}

Within-subjects measurements. All practitioners I speak to have the same request: Please design within-subjects measurements. That is, they wish us to design lie detection methods whereby a decision about the veracity status of an interviewee can be made by 
comparing different responses made within the same interviewee. This request makes perfect sense. Research has shown that truth tellers obtain higher CBCA or RM scores than liars on a group level (Amado et al., 2015, 2016; Masip et al., 2005), but how does this translate to an individual case? CBCA or RM scores are not only affected by the veracity status of the interviewees, but also by their personality (some people are more talkative than others, Merckelbach, 2004; Nahari \& Pazuelo, 2015; Vrij, Akehurst, Soukara, \& Bull, 2002), by the situation (some events are richer in detail than others) or by preparedness (well prepared answers are likely to be longer than spontaneous answers, e.g. Sporer \& Schwandt, 2006). CBCA experts attempt to take external factors into account when evaluating a CBCA score but such attempts are problematic: It is difficult to take all the relevant external factors into account and it is impossible to determine the exact effect of a specific external factor on the CBCA score in question (Vrij, 2005, 2008). The only solution to this problem is to design within-subjects measures and to control for possible external factors within a single interview (Nahari \& Vrij, 2014, 2015; Vrij, 2016).

Fortunately, all four interview protocols discussed in the previous section include within-subjects measures. In SUE, these are changes within a statement (within-statement inconsistencies). In ACID and some CCA techniques, these are the amount of additional details reported after an initial free recall; and in the VA it is the ratio of verifiable / unverifiable details.

Applying within-subjects measures in real life is challenging (Vrij, 2016). These measures would be most effective if truth tellers and liars display truly different response patterns. For example, if truth tellers always include more verifiable than unverifiable details in their statements and liars always more unverifiable than verifiable details. In that case, a clear cut-off score can be established (e.g. each statement with a verifiable details ratio $>1$ is truthful). However, such a cut-off score does not exist and all that can be concluded is that 
truth tellers typically include a higher proportion of verifiable details in their accounts than liars. This still leaves practitioners with the problem when to decide that the proportion of verifiable details is high enough to decide that the interviewee is telling the truth. Yet, using such within-subject measures is still beneficial to using between-subjects measures. It is no longer relevant how detailed an answer is (a between-subjects measure, largely influenced by personality, situation and preparedness), but it becomes relevant how many verifiable and unverifiable details are included (more likely to be influenced by veracity). In sum, the within-subject measures introduced in verbal deception research to date do not provide the ultimate solution, but are an improvement over between-subjects measures.

Refined set of verbal cues to deceit. I believe that the set of verbal cues deception researchers examine could be improved by taking into account the different verbal strategies truth tellers and liars use to appear convincing. In theory, variables that are derived from such strategies should work better for lie detection purposes than those that were not designed for that purpose. I will give two examples that emerged recently from our lab: First, making a distinction between the verbal cues complications, common knowledge details and selfhandicapping strategies, and, second, making a distinction between core details and peripheral details. I will compare these new dependent variables with 'total details', which is frequently used by deception researchers. An additional benefit of these new variables is that they can be used as within-subjects measures.

Truth tellers typically provide more details than liars, because liars lack the imagination to fabricate details that sound plausible, a conclusion derived from the CBCA literature (Köhnken, 2004; Leal et al., 2015), or because they are unwilling to provide many details out of fear that they will give leads to investigators that uncover their lies (Nahari, Vrij, \& Fisher, 2014a). However, total details does not fully take into account the differential verbal strategies truth tellers and liars use, because both truth tellers and liars will provide 
details to sound convincing. Better discrimination will occur if the different type of details truth tellers and liars report are examined. In four experiments, we examined complications, common knowledge details and self-handicapping strategies (Vrij et al., 2017a, 2018a, b, c).

A complication is "an occurrence that makes a situation more difficult than necessary” (“The air conditioning was not working properly in the hotel”) (Vrij et al., 2018b). Truth tellers may report more complications than liars. Research examining liars’ interview strategies showed that liars prefer to keep their stories simple (Hartwig, Granhag, \& Strömwall, 2007), but adding complications makes the story more complex. Common knowledge details refer to strongly invoked stereotypical information about events ("We visited the Louvre museum where we saw the Mona Lisa”) (Vrij et al., 2018b). Liars may report more common knowledge details than truth tellers (Sporer, 2016; Volbert \& Steller, 2014; Vrij et al., 2017a), because liars lack the personal experiences to include in their stories (DePaulo, Kashy, Kirkendol, Wyer, \& Epstein, 1996). Self-handicapping strategies refer to justifications as to why someone is not able to provide information (“I can’t remember; it was a while ago when this happened” (Vrij et al., 2018b). Liars are more likely to include selfhandicapping strategies in their statements than truth tellers. For them not having to provide information is an attractive strategy, because it keeps their stories simple. However, they appear suspicious when they do not provide enough information. A potential solution is to provide a justification for the inability to provide information. Based on the three cues the proportion of complications (complications / [complications + common knowledge details + self-handicapping strategies]) can be calculated, which represents the proportion of cues to truthfulness. It should be higher for truth tellers than for liars.

We found support for most of the predictions (Vrij et al., 2017a, 2018a, b, c): (i) Truth tellers reported more complications than liars, (ii) liars reported more self-handicapping strategies than truth tellers; (iii) the proportion of complications was higher for truth tellers 
than for liars, and (iv) this proportion score was a more diagnostic cue to deceit than the total number of details. The only unexpected finding was that truth tellers and liars did not differ in reporting common knowledge details. My (untested) assumptions are that truth tellers also sometimes report events in a scripted manner, particularly if they misunderstand how much information they are required to report, or when they feel that the events were not important enough to be described in much detail.

A second differentiation in total details that takes truth tellers' and liars' strategies better into account is distinguishing between core and peripheral details (Leal, Vrij, Deeb, \& Jupe, 2018a). Core details are details that, if changed, can result in changes in the basic and most important parts of the story; details that have no such impact are considered peripheral (Heuer \& Reisberg, 1990). Thus, if someone describes attending an Adele concert, all details about the actual concert are core details whereas information about, for example, drinks in the pub before the concert, are peripheral. Truth tellers, who experienced the core event, should be able to provide more core and peripheral information, by employing a 'tell it all strategy’ (Hartwig, Granhag, \& Strömwall, 2007). For liars, who have not experienced the core event, providing false core information may provide leads that investigators can check. Providing false peripheral information seems less incriminating and therefore more desirable. In the only experiment examining core and peripheral details to date, liars indeed reported more peripheral information than truth tellers (Leal et al., 2018a).

Cross-cultural deception Research examining interview techniques to detect deception has typically been conducted in the USA and Western Europe. However, investigators across the world are often interested in how these research findings travel across cultures. In cross-cultural deception research, we can examine differences between cultures. These are for lie detection purposes not relevant, more interesting is whether cues to deceit differ between cultures (Leal et al., 2018b). This seems not to be the case for complications 
and the proportion of complications. Compared to liars, truth tellers reported more complications and obtained a higher proportion of complications in a British sample (Vrij et al., 2018b) and in studies that included a mixture of Russian, South-Korean and Hispanic participants (Vrij et al., 2017a, 2018a, c). In contrast, Taylor and colleagues who examined cues such as first person pronouns and spatial information did find differences between groups (Taylor, Larner, Conchie, \& Menacere, 2017; Taylor, Larner, Conchie, \& van der Zee, 2014). For example, they found a decrease in first person pronouns to be a sign of deceit moderated by culture. That is, lying White British participants reduced their first person pronouns to the greatest extent and North African participants to the least extent, whereas White European and South Asian participants performed in between those two groups (Taylor et al., 2017).

In today’s world where people travel extensively, investigators and interviewees often do not share the same first language. In such circumstances interpreters are frequently used (Russano, Meissner, Narchet, \& Kassin, 2005; Russano, Narchet, \& Kleinman, 2014). There is little research on the effect of the presence of an interpreter on the amount of information provided and the occurrence of verbal cues to deceit, but we have examined this over the past five years in five experiments (Ewens et al., 2016a, b, 2017; Vrij et al., 2017a, 2018a, c). One main finding was that interpreter-present interviews resulted in less information than interpreter-absent interviews (Ewens et al., 2016a, b; Vrij et al., 2017a), possibly due to at least three reasons. First, interpreters may not translate every single detail an interviewee provides. Second, interviewees may choose to be concise when talking through an interpreter as it will take up a lot of time otherwise. Third, the interpreter's translations in an interview interrupt the interviewee’s recall and these interruptions may impair memory retrieval (Nelson \& Goodmon, 2003; Vrij, Hope, \& Fisher, 2014). A second main finding was that the verbal cues to deceit tended to be somewhat weaker in interpreter-present interviews than in 
interpreter-absent interviews (Ewens et al., 2016a, b, 2017; Vrij et al., 2017a, 2018a, b), possibly because in interpreter-present interviews, liars have more opportunity to think (when the interpreter translates their answers).

Less stereotypical interview settings. Standard deception experiments are carried out under specific circumstances (Vrij et al., 2017b). Typically, truth tellers and liars are interviewed just once, and this happens immediately after experiencing an event, with the event being meaningful (or made meaningful) in some way to both truth tellers and liars (Vrij, 2008). In addition, truth tellers and liars are often encouraged to be fully cooperative and to either tell the entire truth (truth tellers) or to be deceptive in most part of their statement (liars). This context may not reflect all real-life situations involving deception. For example, sometimes individuals are interviewed after a delay, and they may be interviewed multiple times. Also, the incident of interest may not have been important for truth tellers and therefore may not have attracted their full attention. In addition, interviewees may not be fully cooperative, and, finally, liars' statements may be mostly based on the truth (embedded lies, Leins, Fisher, \& Ross, 2013).

We recently started to examine some of these alternative circumstances. We found that, if truth tellers and liars were interviewed after a delay, the variable total details became a less diagnostic indicator of deceit, because truth tellers showed a memory decline, whereas liars displayed a stability bias — that is, a failure to accurately calibrate their verbal output to take account of well-established patterns of forgetting over time (Harvey, Vrij, Hope, Mann, \& Leal, 2017). In addition, truth tellers who had incidentally encoded an event provided fewer details than truth tellers who had intentionally encoded the event, and the incidental truth tellers did not differ much in providing details from liars (Harvey, Vrij, Leal, Hope, \& Mann, 2017). These findings do not suggest that over time differences between truth tellers and liars 
in providing details will disappear, rather it suggests that such differences will become less pronounced.

The few studies examining multiple interviews have shown that differences between truth tellers and liars in consistency are modest at best. When differences exist, liars appear to be more consistent than truth tellers, which is at variance with the stereotypical belief that liars are more inconsistent than truth tellers (Vredeveldt, van Koppen, \& Granhag, 2014). However, this finding is in line with the repeat versus reconstruct hypothesis (Granhag \& Strömwall, 1999, 2000). Liars need to keep track of their lies and try to repeat what they have said before, whereas truth tellers rely on their memory of the event. The latter leads to changes because memory is a reconstructive process (Fisher, Vrij, \& Leins, 2013). Liars’ consistency also depends on the interview style. For example, if liars become aware after an initial statement that investigators possess a certain piece of evidence, they may then change their subsequent statement so that they can try to "explain away" this piece of evidence (see the SUE approach discussed earlier; Granhag \& Hartwig, 2015).

\section{Conclusion}

Over the last 30 years, nonverbal and verbal deception research underwent three paradigm shifts: (i) From analysing behaviour to analysing speech, (ii) from lie detection based on truth tellers' and liars’ different levels of arousal to lie detection based on the different cognitive processes or strategies adopted to appear convincing, and (iii) from passively observing target persons to actively interviewing them. Those shifts have resulted in significant progress being made in verbal lie detection in particular. I am confident that the new avenues researchers have recently started to explore in this domain will guarantee even further progress in this already quickly developing field. 
The time I spent working on this article was funded by the Centre for Research and Evidence on Security Threats (ESRC Award: ES/N009614/1) 


\section{References}

Alonso-Quecuty, M. L. (1992). Deception detection and Reality Monitoring: A new answer to an old question? In F. Lösel, D. Bender, \& T. Bliesener (Eds.), Psychology and Law: International perspectives (pp 328-332). Berlin, Germany: Walter de Gruyter.

Amado, B. G., Arce, R., Fariña, F. (2015). Undeutsch hypothesis and Criteria Based Content Analysis: A meta-analytic review. The European Journal of Psychology Applied to Legal Context, 7, 3-12. Doi:10.1016/j.ejpal.2014.11.002

Amado, B. G., Arce, R., Fariña, F., \& Vilarino, M. (2016). Criteria-Based Content Analysis (CBCA) reality criteria in adults: A meta-analytic review. International Journali Health Psychology, 16, 201-210. doi.org/10.1016/j.ijchp.2016.01.002.

Bell, B. E., \& Loftus, E. F. (1989). Trivial persuasion in the courtroom: The power of (a few) minor details. Journal of Personality and Social Psychology, 56, 669-679. DOI: 10.1037//00223514.56.5.669

Bogaard, G., Meijer, E. H., \& Vrij, A. (2014). Using an example statement increases information but does not increase accuracy of CBCA, RM, and SCAN. Journal of Investigative Psychology and Offender Profiling, 11, 151-163. Doi: 10.1002/jip.1409

Bond, C. F., \& DePaulo, B. M. (2006). Accuracy of deception judgements. Personality and Social Psychology Review, 10, 214-234. Doi: 10.1207/s15327957pspr1003_2

Bond, C. F., \& Fahey, W. E. (1987). False suspicion and the misperception of deceit. British Journal of Social Psychology, 26, 41-46. Doi: 10.1111/j.2044-8309.1987.tb00759.x

Christ, S., E., Van Essen, D. C. Watson, J. M., Brubaker, L. E., \& McDermott, K. B. (2009). The Contributions of Prefrontal Cortex and Executive Control to Deception: Evidence from Activation Likelihood Estimate Meta-analyses. Cerebral Cortex, 19, 1557-1566. doi:10.1093/cercor/bhn189. 
Colwell, K., Hiscock-Anisman, C. K., \& Fede, J. (2013). Assessment Criteria Indicative of Deception: An example of the new paradigm of differential recall enhancement. In B. S. Cooper, D. Griesel, \& M. Ternes (Eds.) Applied issues in investigative interviewing, eyewitness memory, and credibility assessment (pp. 259-292). Springer: New York. Doi 10.1007/978-1-4614-5547-9_11.

Colwell, K., Hiscock-Anisman, C. K., Memon, A., Taylor, L., \& Prewett, J. (2007). Assessment criteria indicative of deception (ACID): An integrated system of investigative interviewing and detecting deception. Journal of Investrigative Psychology and Offender Profiling, 4, 167-180. DOI 10.1002/jip.73

Debey, E., Verschuere, B., \& Crombez, G. (2012). Lying and executive control: An experimental investigation using ego depletion and goal neglect. Acta Psychologica, 140, 133-141. DOI: 10.1016/j.actpsy.2012.03.004.

DePaulo, B. M., Kashy, D. A., Kirkendol, S. E., Wyer, M. M., \& Epstein, J. A. (1996). Lying in everyday life. Journal of Personality and Social Psychology, 70, 979-995. DOI org/10.1037/0022-3514.70.5.979

DePaulo, B. M., Lindsay, J. L., Malone, B. E., Muhlenbruck, L., Charlton, K., \& Cooper, H. (2003). Cues to deception. Psychological Bulletin, 129, 74-118. Doi: 10.1037/0033-2909.129.1.74

Ekman, P. (1985). Telling lies: Clues to deceit in the marketplace, politics and marriage. New York: W. W. Norton. (Reprinted in 1992, 2001 and 2009).

Evans, J. R., Michael, S. W., Meissner, C. A., \& Brandon, S. E. (2013). Validating a new assessment method for deception detection: Introducing a Psychologically Based Credibility Assessment Tool. Journal of Applied Research in Memory and Cognition, 2, 33-41. Doi: 10.1016/j/jarmac.2013.02.002. 
Ewens, S., Vrij, A., Leal, S., Mann, S., Jo, E., \& Fisher, R. P. (2016a). The effect of interpreters on eliciting information, cues to deceit and rapport. Legal and Criminological Psychology, 21, 286-304. Doi: 10.1111/lcrp.12067.

Ewens, S., Vrij, A., Leal, S., Mann, S., Jo, E., \& Houston, K. (2017). The effect of the presence and seating position of an interpreter on eliciting information and cues to deceit. Psychology, Crime, \& Law, 23, 180-200. Doi:10.1080/1068316X.2016.1239100

Ewens, S., Vrij, A., Leal, S., Mann, S., Jo, E., Shaboltas, A., Ivanova, M., Granskaya, J., \& Houston, K. (2016b). Using the model statement to elicit information and cues to deceit from native speakers, non-native speakers and those talking through an interpreter. Applied Cognitive Psychology, 30, 854-862. Doi: 10.1002/acp.3270

Fisher, R. P. (2010). Interviewing cooperative witnesses. Legal and Criminological Psychology, 15, 2538. Doi: 10.1348/135532509X441891

Granhag, P.A. \& Hartwig, M. (2008). A new theoretical perspective on deception detection: On the psychology of instrumental mind-reading. Psychology, Crime \& Law, 14, 189-200. DOI: 10.1080/10683160701645181

Granhag, P. A., \& Hartwig, M. (2015). The Strategic Use of Evidence (SUE) technique: A conceptual overview. In P. A. Granhag, A. Vrij, \& B. Verschuere (Eds.), Deception detection: Current challenges and new approaches (pp. 231-251). Chichester, England: Wiley.

Granhag, P. A., \& Strömwall, L. A. (1999). Repeated interrogations: Stretching the deception detection paradigm. Expert Evidence: The International Journal of Behavioural Sciences in Legal Contexts, 7, 163-174. Doi:10.1023/A:1008993326434

Granhag, P. A., \& Strömwall, L. A. (2000). "Let's go over this again...": Effects of repeated interrogations on deception detection performance. In A. Czerederecka, T. JaskiewiczObydzinska, \& J. Wojcikiewicz (Eds.), Forensic psychology and law: Traditional questions and new ideas (pp. 191-196). Krakow, Poland: Institute of Forensic Research Publishers. 
Hartwig, M., Granhag, P. A., \& Luke, T. (2014). Strategic use of evidence during investigative interviews: The state of the science. In: Raskin, D.C., Honts, C.R., Kircher, J.C. (Eds.), Credibility Assessment: Scientific Research and Applications (pp. 1-36). Academic Press.

Hartwig, M., Granhag, P. A., \& Strömwall, L. (2007). Guilty and innocent suspects’ strategies during police interrogations. Psychology, Crime, \& Law, 13, 213-227. Doi: $10.1080 / 10683160600750264$

Hartwig, M., Granhag, P. A., Strömwall, L, \& Doering, N. (2010). Impression and information management: On the strategic self-regulation of innocent and guilty suspects. The Open Criminology Journal, 3, 10-16 (special issue on deception research).

Harvey, A., Vrij, A., Hope, L., Leal, S., \& Mann, S. (2017). A stability bias effect amongst deceivers. Law and Human Behavior, 41, 519-529. Doi: 10.1037/lhb000025

Harvey, A., Vrij, A., Nahari, G.. \& Ludwig, K. (2016). Applying the Verifiability Approach to insurance claims settings: Exploring the effect of the information protocol. Legal and Criminological Psychology. DOI: 10.1111/lcrp.12092

Harvey, A., Vrij, A., Leal, S., Hope, L., \& Mann, S. (2017). Deception and decay: Verbal lie detection as a function of delay and encoding quality. Journal of Applied Research in Memory and Cognition, 6, 306-318. Doi: 10.1016/j. jarmac.2017.04.002

Heuer, F. \& Reisberg, D. (1990). Vivid memories of emotional events: The accuracy of remembered minutiae. Memory \& Cognition, 18: 496-506. Doi: 10.3758/BF03198482.

Inbau, F. E., Reid, J. E., Buckley, J. P., \& Jayne, B. C. (2013). Criminal interrogation and confessions, $5^{\text {th }}$ edition. Burlington, MA: Jones \& Bartlett Learning.

Johnson, M. K. (1988). Reality Monitoring: An experimental phenomenological approach. Journal of Experimental Psychology: General, 117, 390-394. Doi: 10.1037/0096-3445.117.4.390 
Johnson, M. K. (2006). Memory and reality. American Psychologist, 61, 760-771. Doi: 10.1037/0003066X.61.8.760.

Kassin, S. M., \& Fong, C. T. (1999). “I’m innocent!”: Effects of training on judgments of truth and deception in the interrogation room. Law and Human Behavior, 23, 499-516. Doi: 10.1023/A:1022330011811

Köhnken, G. (2004). Statement Validity Analysis and the ‘detection of the truth’. In P. A. Granhag \& L. A. Strömwall (Eds.), Deception detection in forensic contexts (pp. 41-63). Cambridge, England: Cambridge University Press.

Köhnken, G., \& Steller, M. (1988). The evaluation of the credibility of child witness statements in German procedural system. In G. Davies \& J. Drinkwater (Eds.), The child witness: Do the courts abuse children? (Issues in Criminological and Legal Psychology, no. 13) (pp. 37-45). Leicester, United Kingdom: British Psychological Society.

Lancaster, G. L. J., Vrij, A., Hope, L., \& Waller, B. (2012). Sorting the liars from the truth tellers: The benefits of asking unanticipated questions. Applied Cognitive Psychology, 27, 107-114. DOI: 10.1002/acp.2879

Leal, S., Vrij, A., Deeb, H., \& Jupe, L. (2018a). Using the model statement to elicit verbal differences between truth tellers and liars: The benefit of examining core and peripheral details. Manuscript submitted for publication.

Leal, S., Vrij, A., Vernham, Z., Dalton, G., Jupe, L., Harvey, A., \& Nahari, G. (2018b). Crosscultural verbal deception. Legal and Criminological Psychology. Doi: 10.1111/lcrp.12131

Leal, S., Vrij, A., Warmelink, L., Vernham, Z., \& Fisher, R. (2015). You cannot hide your telephone lies: Providing a model statement as an aid to detect deception in insurance telephone calls. Legal and Criminological Psychology, 20, 129-146. Doi: 10.1111/lcrp.12017

Leins, D., Fisher, R. P., \& Ross, S. J. (2013). Exploring liars’ strategies for creating deceptive reports. Legal and Criminological Psychology, 18, 141-151. DOI: 10.1111/j.2044-8333.2011.02041.x 
Mann, S., Vrij, A., \& Bull, R. (2002). Suspects, lies and videotape: An analysis of authentic highstakes liars. Law and Human Behavior, 26, 365-376. Doi: 10.1023/A:1015332606792

Mann, S., Vrij, A., \& Bull, R. (2004). Detecting true lies: Police officers' ability to detect deceit. Journal of Applied Psychology, 89, 137-149. Doi: 10.1037/0021-9010.89.1.137

Mann, S., Vrij, A., Fisher, R. \& Robinson, M. (2008). See no lies, hear no lies: Differences in discrimination accuracy and response bias when watching or listening to police suspect interviews. Applied Cognitive Psychology, 22, 1062-1071. Doi: 10.1002/acp.1406

Masip, J., Sporer, S., Garrido, E., \& Herrero, C. (2005). The detection of deception with the reality monitoring approach: A review of the empirical evidence. Psychology, Crime, \& Law, 11, 99-122. Doi: 10.1080/10683160410001726356

Meissner, C. A., Redlich, A. D., Michael, S. W., Evans, J. R., Camiletti, C. R., Bhatt, S., \& Brandon, S. (2014). Accusatorial and information-gathering interrogation methods and their effects on true and false confessions: A meta-analytic review. Journal of Experimental Criminology, 10, 459-486. DOI: 10.1007/s11292-014-9207-6

Merckelbach, H. (2004). Telling a good story: Fantasy proneness and the quality of fabricated memories. Personality and Individual Differences, 37, 1371-1382. Doi:10.1016/j.paid. 2004.01.007.

Nahari, G. (2018). The applicability of the Verifiability Approach to the real world. In P. Rosenfeld (Ed.). Detecting concealed information and deception: Verbal, behavioral, and biological methods (pp. 329-350). San Diego, CA: Academic Press. Doi: 10.1016/B978-0-12-8127292.00014-8.

Nahari, G., \& Pazuelo, M. (2015). Telling a convincing story: Richness in detail as a function of gender and priming. Journal of Applied Research in Memory and Cognition, 4 , 363-367. Doi: 10.1016/j.jarmac.2015.08.005 
Nahari, G. \& Vrij, A. (2014). Are you as good as me at telling a story? Individual differences in interpersonal-Reality Monitoring. Psychology, Crime, \& Law, 20, 573-583.

Doi:10.1080/1068316X.2013.793771

Nahari, G., \& Vrij, A. (2015). Systematic errors (biases) in applying verbal lie detection tools: richness in detail as a test case. Crime Psychology Review, 1, 98-107. Doi: 10.1080/23744006.2016.115809.

Nahari, G., Vrij, A., \& Fisher, R. P. (2012). Does the truth come out in the writing? SCAN as a lie detection tool. Law \& Human Behavior, 36, 68-76. Doi: 10.1007/s10979-011-9264-6

Nahari, G., Vrij, A., \& Fisher, R. P. (2014a). Exploiting liars’ verbal strategies by examining unverifiable details. Legal and Criminological Psychology, 19, 227 - 239. doi: 10.1111/j.2044-8333.2012.02069.x

Nahari, G., Vrij, A., \& Fisher, R. P. (2014b). The verifiability approach: Countermeasures facilitate its ability to discriminate between truths and lies. Applied Cognitive Psychology, 28, 122 128.doi: 10.1002/acp.2974

National Research Council (2003). The polygraph and lie detection. Committee to Review the Scientific Evidence on the Polygraph. Washington, DC: The National Academic Press.

Nelson, D. L., \& Goodmon, L. B. (2003). Disrupting attention: The need for retrieval cues in working memory theories. Memory and Cognition, 31, 65-76. Doi: 10.3758/BF03196083

Reid, J. E., \& Arther, R. O. (1953). Behavior symptoms of lie-detector subjects. Journal of Criminal Law, Criminology and Police Science, 44, 104-108.

Russano, M. B., Meissner, C. A., Narchet, F. M., \& Kassin, S. M. (2005). Investigating true and false confessions with a novel experimental paradigm. Psychological Science, 16, 481-486. DOI:10.1111/j.0956-7976.205.01560x. 
Russano, M. B., Narchet, F. M., \& Kleinman, S. M. (2014). Analysts, interpreters and intelligence interrogations: Perceptions and insights. Applied Cognitive Psychology, 28: 829-846. DOI: 10.1002/acp.3070.

Sporer, S. L. (1997). The less travelled road to truth: Verbal cues in deception detection in accounts of fabricated and self-experienced events. Applied Cognitive Psychology, 11, 373-397.

Doi:10.1002/(SICI)1099-0720(199710)11:5<373::AID-ACP461>3.0.CO;2-0

Sporer, S. L. (2004). Reality monitoring and detection of deception. In P. A. Granhag \& L. A.

Strömwall (Eds.), Deception detection in forensic contexts (pp. 64-102). Cambridge, England: Cambridge University Press.

Sporer, S. L. (2016). Deception and cognitive load: Expanding our horizon with a working memory model. Frontiers in Psychology: Hypothesis and Theory, 7, article 420. DOI 10.3389/fpsyg.2016.00420.

Sporer, S. L., \& Schwandt, B. (2006). Paraverbal indicators of deception: A meta-analytic synthesis. Applied Cognitive Psychology, 20, 421-446. Doi: 10.1002/acp.1190

Taylor, P. J., Larner, S., Conchie, S. M., \& Menacere, T. (2017). Culture moderates changes in linguistic self-presentation and detail provision when deceiving others. Royal Society Open Science, 4, 170128. doi: 10.1098/rsos.170128.

Taylor, P. J., Larner, S., Conchie, S. M., \& van der Zee, S. (2014). Cross-cultural deception detection. In P. A. Granhag, A. Vrij, \& B. Verschuere (Eds.), Detecting deception: Current challenges and cognitive approaches (pp. 175-201). Chichester, UK: John Wiley \& Sons.

Verschuere, B., Köbis, N.C., Bereby-Meyer, Y., Rand, D., \& Shalvi, S. (2018). Taxing the brain to uncover lying? Meta-analyzing the effect of imposing cognitive load on the reaction-time costs of lying. Journal of Applied Memory \& Cognition. Doi: 10.1016/j.copsyc.2015.09.004

Volbert, R., \& Steller, M. (2014). Is this testimony truthful, fabricated, or based on false memory? 
Credibility assessment 25 years after Steller and Köhnken (1989). European Psychologist, 19, 207-220. doi:10.1027/1016-9040/a000200.

Vredeveldt, A., van Koppen, P. J., \& Granhag, P. A. (2014). The inconsistent suspect: A systematic review of different types of consistency in truth tellers and liars. In R. Bull (Ed.), Investigative Interviewing (pp. 183-207). New York: Springer Science+Business Media DOI 10.1007/978-1-4614-9642-7_10

Vrij, A. (2005). Criteria-Based Content Analysis: A qualitative review of the first 37 studies. Psychology, Public Policy, and Law, 11, 3-41. Doi: 10.1037/1076-8971.11.1.3

Vrij, A. (2008). Detecting lies and deceit: Pitfalls and opportunities, second edition. Chichester: John Wiley and Sons.

Vrij, A. (2016). Baselining as a lie detection method. Applied Cognitive Psychology, 30, 1112-1119. Doi: 10.1002/acp.3288

Vrij, A. (2018). Verbal lie detection tools from an applied perspective. In J. P. Rosenfeld (Ed.), Detecting concealed information and deception: Recent developments (pp. 297-321). San Diego, CA: Elsevier: Academic Press. Doi: 10.1016/B978-0-12-812729-2.00013-6

Vrij, A., Akehurst, L., Soukara, S., \& Bull, R. (2002). Will the truth come out? The effect of deception, age, status, coaching, and social skills on CBCA scores. Law and Human Behaviour, 26, 261283. Doi:10.1023/A:1015313120905

Vrij, A., Fisher, R., Blank, H. (2017). A cognitive approach to lie detection: A meta-analysis. Legal and Criminological Psychology, 22, 1-21. Doi:10.1111/lcrp.12088

Vrij, A., Fisher, R., Blank, H., Leal, S., \& Mann, S. (2016). A cognitive approach to elicit nonverbal and verbal cues of deceit. In J. W. van Prooijen \& P. A. M. van Lange (Eds.), Cheating, corruption, and concealment: The roots of dishonest behavior (pp. 284-310). Cambridge, England: Cambridge University Press. 
Vrij, A., \& Granhag, P. A. (2012). Eliciting cues to deception and truth: What matters are the questions asked. Journal of Applied Research in Memory and Cognition, 1, 110-117. doi.org/10.1016/j.jarmac.2012.02.004

Vrij, A., Hartwig, M., \& Granhag, P. A. (2018). Reading lies: Nonverbal communication and deception. Annual Review of Psychology. Doi: 10.1146/annurev-psych-010418-103135

Vrij, A., Hope, L., \& Fisher, R. P. (2014). Eliciting reliable information in investigative interviews. Policy Insights from Behavioral and Brain Sciences, 1, 129-136. Doi: $10.1177 / 2372732214548592$

Vrij, A., Leal, S., Fisher, R. P., Mann, S., Dalton, G. Jo, E., Shaboltas, A., Khaleeva, M., Granskaya, J., \& Houston, K. (2018a). Sketching as a technique to elicit information and cues to deceit in interpreter-based interviews. Journal of Applied Research in Memory and Cognition, 7, 303313. Doi: 10.1016/j.jrarmac.2017.11.001

Vrij, A., Leal, S., Jupe, L., \& Harvey, A. (2018b). Within-subjects verbal lie detection measures: A comparison between total detail and proportion of complications. Legal and Criminological Psychology. Doi:10.1111/lcrp.12126

Vrij, A., Leal, S., Mann, S., Dalton, G. Jo, E., Shaboltas, A., Khaleeva, M., Granskaya, J., \& Houston, K. (2017a). Using the Model Statement to elicit information and cues to deceit in interpreter-based interviews. Acta Psychologica, 177, 44-53. Doi:

10.1016/j.actpsy.2017.04.011

Vrij, A., Leal, S., Mann, S., Fisher, R. P., Dalton, G. Jo, E., Shaboltas, A., Khaleeva, M., Granskaya, J., \& Houston, K. (2018c). Using unexpected questions to elicit information and cues to deceit in interpreter-based interviews. Applied Cognitive Psychology, 32, 94-104. Doi: 10.1002/acp.3382 
Vrij, A., Mann, S., Leal, S., \& Granhag, P. A. (2010). Getting into the minds of pairs of liars and truth tellers: An examination of their strategies. The Open Criminology Journal, 3, 17-22. Doi: 10.2174/1874917801003010017 (special issue on deception research).

Vrij, A., Meissner, C. A, Fisher, R. P., Kassin, S. M., Morgan III, A., \& Kleinman, S. (2017b). Psychological perspectives on interrogation. Perspectives on Psychological Science, 12, 927955. doi: 10.1177/ 1745691617706515

Vrij, A. \& Nahari, G. (in press). The Verifiability Approach In J. J. Dickinson, N. Schreiber Compo, R. N. Carol, B. L. Schwartz, \& M. R. McCauley (Eds.) Evidence-Based Investigative Interviewing. New York, U.S.A.: Routledge Press.

Yegiyan, N. S. \& Lang, A. (2010). Processing central and peripheral detail: How content arousal and emotional tone influence encoding. Media Psychology, 13, 77-99. Doi:

10.1080/15213260903563014 